\title{
Effect of Low-Density Lipoprotein Cholesterol Goal Achievement on Vascular Physiology Evaluated by Quantitative Flow Ratio in Patients Underwent Percutaneous Coronary Intervention
}

\section{Long Chen}

Fujian Medical University Union Hospital

Jiaxin Zhong

Fujian Medical University Union Hospital

Zhen Ye

Fujian Medical University Union Hospital

Qin Chen

Fujian Medical University Union Hospital

Mingfang Ye

Fujian Medical University Union Hospital

\section{Yuanming Yan}

Fujian Medical University Union Hospital

Yukun Luo ( $\nabla$ luoyukun@hotmail.com )

Fujian Medical University Union Hospital https://orcid.org/0000-0002-9741-1687

\section{Research Article}

Keywords: percutaneous coronary intervention, low-density lipoprotein cholesterol goal, quantitative flow ratio, coronary physiology, physiological restenosis

Posted Date: February 25th, 2021

DOl: https://doi.org/10.21203/rs.3.rs-235797/v1

License: (9) This work is licensed under a Creative Commons Attribution 4.0 International License. Read Full License 


\section{Abstract \\ Purpose}

The change in coronary physiology from lipid-lowing therapy(LLT)lacks an appropriate examination method. Quantitative flow ratio (QFR) is a novel angiography-based method allowing fast assessment of coronary physiology. This study sought to determine the impact of the low-density lipoprotein cholesterol (LDL-C) goal achievement on coronary physiology through QFR.

\section{Methods}

Patients who underwent percutaneous coronary intervention (PCI) and one-year angiographic follow-up were screened and computed by QFR analysis. According to the LDL-C level at one-year follow-up, patients were divided into two groups:1) goal-achievement group (LDL-C $<1.8 \mathrm{mmol} / \mathrm{l}$ or reduction of $\geq$ $50 \%, n=146$, lesion $=165) ; 2)$ non-achievement group $(n=286$, lesion $=331)$. All QFR data and major adverse cardiovascular and cerebrovascular events (MACCEs) at one year were compared between groups.

\section{Results}

No differences between the groups were found in quantitative coronary angiography (QCA) data and QFR at post-PCl. At one-year follow-up, lower percentage diameter stenosis (DS \%) and percentage area stenosis (AS \%) were recorded in goal-achievement group ( $27.89 \pm 10.16$ vs. $30.93 \pm 12.03, p=0.010$, $36.57 \pm 16.12$ vs. $41.68 \pm 17.39, p=0.003$, respectively). Meanwhile, a higher QFR was found in goalachieved patients $(0.96 \pm 0.05$ vs. $0.94 \pm 0.09, p=0.005)$. Furthermore, goal-achievement group had a lower incidence of physiological restenosis and MACCEs ( $2.1 \%$ vs. $8.4 \%, p=0.018,5.4 \%$ vs. $12.6 \%, p=$ 0.021 , respectively).

\section{Conclusions}

Evaluated by QFR, patients who achieved the LDL-C goal seem to have a better coronary physiological benefit. Meanwhile, this group of patients is presented a better clinical outcome.

\section{Introduction}

Howbeit the prognosis of patients with coronary artery disease (CAD) is well improved by percutaneous coronary intervention $(\mathrm{PCl})$, survival patients still have an increasing risk of recurrent cardiovascular events [1]. Therefore, appropriate disease management is of increasing significance. As a crucial part in cardiac disease management, lipid modification is associated with reduced cardiovascular mortality. It is well-established that lowering low-density lipoprotein cholesterol (LDL-C) concentration among very high- 
risk patients is the primary target to reduce the risk of cardiovascular events [2,3]. Lipid-lowing therapy (LLT) has been the cornerstone of medical therapy for primary and secondary prevention of atherosclerotic cardiovascular disease (ASCVD) $[4,5]$.

The European Society of Cardiology (ESC)/European Atherosclerosis Society (EAS) 2019 guidelines for management of dyslipidemia recommend a LDL-C reduction of $\geq 50 \%$ from baseline and a LDL-C goal of $<1.4 \mathrm{mmol} / \mathrm{l}(<55 \mathrm{mg} / \mathrm{dl})$ in very high cardiovascular disease risk patients (reduced from $<1.8 \mathrm{mmol} / \mathrm{l}$ $(70 \mathrm{~g} / \mathrm{dl})$ in the 2016 guidelines) $[6,3]$. Clinical benefits of LDL-C goal achievement have been demonstrated by numerous landmark studies [7, 8]. In addition to lowering serum cholesterol levels, LLT induces plaque stabilization and improves endothelial function [9]. As novel technologies (i.e., intravascular ultrasound (IVUS), optical coherence tomography (OCT), fractional flow reserve (FFR)) emerging, more precise methods to evaluate outcomes from LLT are gradually enriched. Emerging data obtained by novel imaging modalities suggests that LLT might have a greater impact on modulating lipid content versus plaque volume [10], which makes the multidisciplinary assessment for clinical outcome from LLT be of significant concern. The level of LDL-C and plaque volume can be known from laboratory tests, and the information of plaque composition can be provided by IVUS or OCT. However, the change in coronary physiology from LLT lacks an appropriate examination method.

Yellow trial found that improvements in FFR were observed in patients treated by LLT and this change was independent of results in IVUS [10]. Therefore, it is of considerable importance to coronary physiologic assessment in LLT process. Although FFR can provide information of flow physiology, the measurement of FFR is accompanied with certain problems, such as requiring introduction of an invasive pressure wire, increasing patient discomfort, complication risk and costs associated with the catheterization procedure [11, 12]. Quantitative flow ratio (QFR) is a promising angiography-based approach allowing fast computation of FFR by 3D coronary artery reconstruction and fluid dynamics computation [11]. The accuracy of QFR was verified by previous studies [11, 13, 12], meanwhile, no requirement of pressure wires and quicker procedural time makes QFR become a suitable choice for the evaluation of coronary physiology [12]. Nevertheless, impact of LDL-C goal achievement on vascular physiology evaluated by QFR remains unknown. This study aimed to investigate the changes in coronary physiology in patients who achieved LDL-C goal at one-year follow-up through QFR analysis.

\section{Methods}

\subsection{Study design}

This study was approved by the Ethics Committee of Union Hospital, Fujian Medical University (No.2020KY098). From June 2015 to December 2016, A total of 734 lesions in 606 patients underwent $\mathrm{PCl}$ at Fujian Medical University Union Hospital were recruited. All enrolled patients were computed for QFR, and clinical characteristics of pre-PCl, post-PCl and one-year angiographic follow-up were collected. Post-PCl means the immediate time after successful PCl. 
Patients diagnosed stable angina, unstable angina or post-acute myocardial infarction ( $\geq 72$ hours) were eligible for enrollment when angiographic inclusion criteria were met. Indication for QFR computation was: (1) Diameter stenosis (DS) of at least one lesion between 50-90\% (visual assessment); (2) Reference vessel diameter size $\geq 2.5 \mathrm{~mm}$ (visual assessment). Patients consisting any of the following clinical characters would be excluded: (1) DS of $<50 \%$ (2) vessels of $<2 \mathrm{~mm}$ of reference diameter; (3) lack of two optimal angiographic projections at least $25^{\circ}$ apart; (4) bypass graft or myocardial bridge supplying the target vessel; (5) overlapping or tortuous vessels; (6) too much shortening; (7) poor quality image.

In the light of our data acquired from June 2015 to December 2016, a LDL-C value of $<1.8 \mathrm{mmol} / \mathrm{I}$ or a LDL-C reduction of $\geq 50 \%$ was chosen as a LDL-C goal based on 2016 ESC/EAS Guidelines for the Management of Dyslipidaemias [6]. According to LDL-C level at the time of one-year follow-up, all subjects were divided into two groups: (1) goal-achievement group (patients achieved a LDL-C goal); (2) non-achievement group (patients failed to achieve a LDL-C goal).

\subsection{QFR computation and quantitative coronary angiography (QCA) analysis}

The QFR computation and QCA analysis were performed by two independent investigators blinded to clinical data through the AngioPlus system (Pulse Medical Imaging Technology Shanghai, China) according to standard operating procedures. Based on automated contouring, a three-dimensional (3D) QCA model of the target vessel was reconstructed using two angiographic projections recorded at 15 frames/s and at least $25^{\circ}$ apart. Proximal and distal reference points were used to indicate the region of interest, and "flagging" was used to indicate lesion segments. After 3D QCA reconstruction, the vessel QFR was computed by contrast flow velocity models $[14,11]$.In addition, 3D reconstruction of the vessel provides QCA information of target vessel comprising percentage diameter stenosis (DS\%), percentage area stenosis (AS\%) and late lumen loss (LLL). LLL was defined as difference of minimal lumen diameter between post-PCl and follow-up.

\subsection{Data collection and follow-up}

All enrolled patients were recorded for relevant clinical data, laboratory results and major adverse cardiovascular and cerebrovascular events (MACCEs) during their hospitalization and at one-year followup. Serum biochemical results such as LDL-C, N-terminal pro brain natriuretic peptide (NT-proBNP), C reaction protein (CRP), glucose, and creatinine were measured in the hospital clinical laboratory using routine automated techniques.

An MACCE was defined as the composite of any myocardial infarction (MI), stroke, or any ischemiadriven revascularization of target and non-target vessels. The target vessel was defined as the vessel in which the stent was placed during the first angiography. All patients were treated according to clinical guidelines recommendation at the time after discharge. The occurrence of MACCEs within one year was recorded by telephone follow-up and medical record query. 


\subsection{Statistical analysis}

Categorical variables were presented as absolute frequencies and proportions, and were compared using the chi-square test or Fisher's exact test. Continuous variables were expressed as mean \pm standard deviation for normally distributed data and as median (interquartile range) for non-normally distributed data. They were compared using Student's t test or the Mann-Whitney $\mathrm{U}$ test, respectively. In all analyses, value of $<0.05$ was considered statistically significant. All statistical analyses were performed with SPSS 26.0 (IBM Inc., New York, NY, USA).

\section{Results}

\subsection{Baseline characteristics}

A total of 734 lesions in 606 patients underwent $\mathrm{PCl}$ were recruited, and 496 lesions in 432 patients were enrolled in final analysis. According to study design, enrolled patients were divided to goal-achievement group $(n=146$, lesion $=165)$ and non-achievement group $(n=286$, lesion $=331)$, respectively (Fig. 1$)$. The clinical, laboratory, and angiographic characteristics between the groups were summarized in Table 1. By comparison of baseline characteristics, goal-achievement group showed a lower CRP level (1.71(0.60$5.29)$ vs. $2.65(0.89-8.52), p=0.033)$ than non-achievement group. No significant differences were found in age, gender, hypertension, diabetes mellitus, renal insufficiency, smoking, history of previous AMI or $\mathrm{PCl}$, and type of CAD between the two groups. The level of LDL-C, NT-proBNP, glucose, creatinine and left ventricular ejection fraction (LVEF) showed similar results. In addition, both groups had similar medical therapies. 
Table 1

Baseline demographic characteristics

\begin{tabular}{|c|c|c|c|}
\hline & $\begin{array}{l}\text { Goal-achievement group } \\
(n=146)\end{array}$ & $\begin{array}{l}\text { Non-achievement group } \\
(n=286)\end{array}$ & $p$ value \\
\hline Age, years & $63.52 \pm 10.62$ & $62.47 \pm 9.78$ & 0.184 \\
\hline Male, n (\%) & 118(80.8) & 225(78.7) & 0.601 \\
\hline Hypertension, n (\%) & $98(67.1)$ & $173(60.5)$ & 0.319 \\
\hline Diabetes mellitus, n (\%) & $42(28.8)$ & $86(30.1)$ & 0.779 \\
\hline Renal insufficiency, n (\%) & $6(4.1)$ & $8(2.8)$ & 0.466 \\
\hline Current/past smoking, n (\%) & $82(56.2)$ & 156(54.5) & 0.749 \\
\hline Previous MI, n (\%) & 15(10.3) & $33(11.5)$ & 0.692 \\
\hline Previous PCl, n (\%) & $24(16.4)$ & $45(15.7)$ & 0.850 \\
\hline \multicolumn{4}{|l|}{ Medications } \\
\hline Antiplatelet agent, n (\%) & / & / & / \\
\hline Statin, n (\%) & / & / & / \\
\hline ACE-inhibitor/ARB, n (\%) & $108(74)$ & $225(78.7)$ & 0.272 \\
\hline \multicolumn{4}{|c|}{ Type of coronary artery disease } \\
\hline Unstable Angina, n (\%) & $87(59.6)$ & 157(54.9) & 0.352 \\
\hline NSTEMI, n (\%) & $21(14.4)$ & $45(15.7)$ & 0.712 \\
\hline STEMI, n (\%) & 22(15.1) & $52(18.2)$ & 0.417 \\
\hline Stable Angina, n (\%) & 16(10.9) & $32(11.2)$ & 0.943 \\
\hline \multicolumn{4}{|l|}{ Laboratory data } \\
\hline NT-proBNP, pg/mL & $121.00(49.75-624.25)$ & $172.50(66.00-577.75)$ & 0.147 \\
\hline CRP, mg/L & $1.71(0.60-5.29)$ & $2.65(0.89-8.52)$ & 0.033 \\
\hline Glucose, mmol/L & $6.58 \pm 2.64$ & $6.57 \pm 2.73$ & 0.845 \\
\hline Creatinine, umol/L & $83.44 \pm 54.94$ & $78.42 \pm 21.88$ & 0.181 \\
\hline \multicolumn{4}{|c|}{ Values are the mean \pm standard deviation, median(interquartile range), or number (\%). } \\
\hline \multicolumn{4}{|c|}{$\begin{array}{l}\text { MI, myocardial infarction; PCI, percutaneous coronary intervention; ACE-inhibitor, angiotensin- } \\
\text { converting-enzyme inhibitor; ARB, angiotensin II receptor blocker; NSTEMI, Non-ST segment elevation } \\
\text { myocardial infarction; STEMI, ST segment elevation myocardial infarction; LDL-C, low-density } \\
\text { lipoprotein cholesterol; NT-proBNP, N-terminal pro brain natriuretic peptide; CRP, C-reaction protein; } \\
\text { LVEF, left ventricular ejection fraction. }\end{array}$} \\
\hline
\end{tabular}




\begin{tabular}{|c|c|c|c|}
\hline & $\begin{array}{l}\text { Goal-achievement group } \\
(n=146)\end{array}$ & $\begin{array}{l}\text { Non-achievement group } \\
(\mathrm{n}=286)\end{array}$ & $p$ value \\
\hline LDL-C, mmol/L & $2.81 \pm 1.07$ & $2.93 \pm 0.93$ & 0.138 \\
\hline LVEF, \% & $61.83 \pm 11.76$ & $60.47 \pm 10.71$ & 0.194 \\
\hline \multicolumn{4}{|c|}{ Values are the mean \pm standard deviation, median(interquartile range), or number (\%). } \\
\hline \multicolumn{4}{|c|}{$\begin{array}{l}\text { MI, myocardial infarction; PCI, percutaneous coronary intervention; ACE-inhibitor, angiotensin- } \\
\text { converting-enzyme inhibitor; ARB, angiotensin II receptor blocker; NSTEMI, Non-ST segment elevation } \\
\text { myocardial infarction; STEMI, ST segment elevation myocardial infarction; LDL-C, low-density } \\
\text { lipoprotein cholesterol; NT-proBNP, N-terminal pro brain natriuretic peptide; CRP, C-reaction protein; } \\
\text { LVEF, left ventricular ejection fraction. }\end{array}$} \\
\hline
\end{tabular}

\subsection{QCA and QFR analysis results}

All QCA and QFR analysis data were summarized in Table 2. The goal-achievement group had a higher proportion of target lesion located in right coronary artery $(32.7 \%$ vs. $27.2 \%, p=0.034)$, while similar proportions in left anterior descending branch and left circumflex branch. There were no differences in QCA data and QFR between the groups at post-PCI time. However, goal-achievement group showed a lower DS\% (27.89 \pm 10.16 vs. $30.93 \pm 12.03, p=0.010)$ and $A S \%(36.57 \pm 16.12$ vs. $41.68 \pm 17.39, p=$ 0.003 ) at the time of one-year follow-up. Meantime, QFR in goal-achievement group was higher than in non-achievement group $(0.96 \pm 0.05$ vs. $0.94 \pm 0.09, p=0.005)$. To compare the difference in physiological outcomes, the incidence of physiological restenosis (QFR $\leq 0.8$ ) was recorded on the basis of QFR value at the time of follow-up. (Table 3). Goal-achievement group showed a lower incidence of physiological restenosis than non-achievement group $(2.1 \%$ vs. $8.4 \%, p=0.018)$. However, not all patients who confirmed a physiological restenosis received an actual occurring revascularization due to the lack of coronary physiological assessment at that time. 
Table 2

QCA and QFR analysis results

\begin{tabular}{|c|c|c|c|}
\hline & $\begin{array}{l}\text { Goal-achievement group } \\
(n=165)\end{array}$ & $\begin{array}{l}\text { Non-achievement group } \\
(\mathrm{n}=331)\end{array}$ & $p$ value \\
\hline \multicolumn{4}{|l|}{ Target lesion location } \\
\hline LAD, n (\%) & $89(53.9)$ & $186(56.2)$ & 0.354 \\
\hline LCX, n (\%) & 22(13.3) & $55(16.6)$ & 0.668 \\
\hline RCA, n (\%) & $54(32.7)$ & $90(27.2)$ & 0.034 \\
\hline \multicolumn{4}{|l|}{ Post-PCl } \\
\hline Diameter stenosis, \% & $27.26 \pm 11.61$ & $27.61 \pm 11.20$ & 0.766 \\
\hline Area stenosis, \% & $34.93 \pm 16.83$ & $36.22 \pm 16.51$ & 0.500 \\
\hline QFR & $0.96 \pm 0.07$ & $0.96 \pm 0.07$ & 0.914 \\
\hline \multicolumn{4}{|l|}{ One-year follow-up } \\
\hline Diameter stenosis, \% & $27.89 \pm 10.16$ & $30.93 \pm 12.03$ & 0.010 \\
\hline Area stenosis, \% & $36.57 \pm 16.12$ & $41.68 \pm 17.39$ & 0.003 \\
\hline Late lumen loss, mm a & $0.07 \pm 0.50$ & $0.16 \pm 0.48$ & 0.172 \\
\hline QFR & $0.96 \pm 0.05$ & $0.94 \pm 0.09$ & 0.005 \\
\hline \multicolumn{4}{|c|}{ Values are the mean \pm standard deviation or number(\%). } \\
\hline \multicolumn{4}{|c|}{$\begin{array}{l}\text { QCA, quantitative coronary angiography; QFR, quantitative flow rate; LAD, left anterior descending } \\
\text { branch; LCX, left circumflex branch; RCA, right coronary artery; }\end{array}$} \\
\hline
\end{tabular}


Table 3

Incidence of physiological restenosis

\begin{tabular}{|c|c|c|c|c|}
\hline $\begin{array}{l}\text { Case } \\
\text { NO. }\end{array}$ & Age(years)/gender & $\begin{array}{l}\text { Target } \\
\text { vessel }\end{array}$ & $\begin{array}{l}\text { Oneyear follow-up LDL- } \\
\mathrm{C}(\mathrm{mmol} / \mathrm{L})\end{array}$ & $\begin{array}{l}\text { One-year follow-up } \\
\text { QFR }\end{array}$ \\
\hline \multicolumn{5}{|c|}{ Goal-achievement group } \\
\hline 1 & $71 / F$ & LAD & 1.36 & 0.67 \\
\hline 2 & $64 / M$ & LAD & 1.69 & 0.71 \\
\hline 3 & $79 / \mathrm{M}$ & RCA & 1.27 & 0.78 \\
\hline \multicolumn{5}{|c|}{ Non-achievement group } \\
\hline 4 & $85 / \mathrm{M}$ & LAD & 2.44 & 0.26 \\
\hline 5 & $54 / \mathrm{M}$ & LAD & 2.55 & 0.47 \\
\hline 6 & $64 / F$ & LAD & 2.06 & 0.53 \\
\hline 7 & $54 / F$ & LAD & 2.64 & 0.53 \\
\hline 8 & $51 / M$ & LAD & 2.1 & 0.63 \\
\hline 9 & $61 / M$ & RCA & 2.17 & 0.65 \\
\hline 10 & $65 / F$ & LAD & 2.85 & 0.67 \\
\hline 11 & $46 / F$ & LAD & 2.53 & 0.68 \\
\hline 12 & $61 / M$ & RCA & 2.65 & 0.71 \\
\hline 13 & $73 / \mathrm{M}$ & LAD & 2.47 & 0.72 \\
\hline 14 & $71 / \mathrm{M}$ & RCA & 3.54 & 0.72 \\
\hline 15 & $76 / \mathrm{M}$ & LAD & 3.92 & 0.72 \\
\hline 16 & $59 / \mathrm{M}$ & LCX & 1.87 & 0.73 \\
\hline 17 & $45 / F$ & RCA & 2.74 & 0.73 \\
\hline 18 & $48 / \mathrm{M}$ & LAD & 2.6 & 0.73 \\
\hline 19 & $54 / \mathrm{M}$ & LCX & 1.99 & 0.74 \\
\hline 20 & $58 / \mathrm{M}$ & LAD & 1.86 & 0.76 \\
\hline 21 & $46 / \mathrm{M}$ & LAD & 1.94 & 0.76 \\
\hline 22 & $61 / M$ & LAD & 2.2 & 0.77 \\
\hline
\end{tabular}

LDL-C, low-density lipoprotein cholesterol; QFR, quantitative flow rate; LAD, left anterior descending artery; LCX, left circumflex artery; RCA, right coronary artery; Physiological restenosis means vessel QFR $\leq 0.8$ at the time of one-year angiographic follow-up. 


\begin{tabular}{|lllll|}
\hline $\begin{array}{l}\text { Case } \\
\text { NO. }\end{array}$ & Age(years)/gender & $\begin{array}{l}\text { Target } \\
\text { vessel }\end{array}$ & $\begin{array}{l}\text { One-year follow-up LDL- } \\
\text { C(mmol/L) }\end{array}$ & $\begin{array}{l}\text { One-year follow-up } \\
\text { QFR }\end{array}$ \\
\hline 23 & $45 / \mathrm{M}$ & LAD & 2.76 & 0.77 \\
\hline 24 & $60 / \mathrm{M}$ & LAD & 2.05 & 0.78 \\
\hline 25 & $63 / \mathrm{M}$ & LAD & 1.87 & 0.79 \\
\hline 26 & $66 / \mathrm{F}$ & LAD & 2.1 & 0.79 \\
\hline 27 & $52 / \mathrm{M}$ & LAD & 2.15 & 0.79 \\
\hline $\begin{array}{l}\text { LDL-C, low-density lipoprotein cholesterol; QFR, quantitative flow rate; LAD, left anterior descending } \\
\text { artery; LCX, left circumflex artery; RCA, right coronary artery; Physiological restenosis means vessel } \\
\text { QFR } \leq \text { 0.8 at the time of one-year angiographic follow-up. }\end{array}$ \\
\hline
\end{tabular}

\subsection{Clinical outcomes}

Comparison of clinical outcomes at one-year follow-up between the groups were demonstrated in Table 4. A total of 44 patients (10.2\%) were reported with MACCEs, 8 patients of whom was from goalachievement group and 36 patients of whom was from non-achievement group, respectively $(5.4 \% \mathrm{vs}$. $12.6 \%, p=0.021)$ (Table 4).

Table 4

Incidence of MACCES

\begin{tabular}{|c|c|c|c|}
\hline & $\begin{array}{l}\text { Goal-achievement } \\
\text { group } \\
(n=146)\end{array}$ & $\begin{array}{l}\text { Non-achievement group } \\
(n=286)\end{array}$ & $p$ value \\
\hline MACCEs, n (\%) & $8(5.4)$ & $36(12.6)$ & 0.021 \\
\hline MI, n (\%) & 0 & 1 & / \\
\hline TVR, n (\%) & $5(3.4)$ & $17(5.9)$ & 0.266 \\
\hline Non-TVR, n (\%) & $4(2.7)$ & $20(7.0)$ & 0.109 \\
\hline Stroke, n (\%) & 0 & 0 & / \\
\hline \multicolumn{4}{|c|}{ Values are number (\%). } \\
\hline $\begin{array}{l}\text { MACCEs, major } \\
\text { target vessel rel }\end{array}$ & $\begin{array}{l}\text { cardiovascular and } \\
\text { zation; Non-TVR, No }\end{array}$ & $\begin{array}{l}\text { ascular events; MI, myoca } \\
\text { vessel revascularization. }\end{array}$ & tion; TVR, \\
\hline
\end{tabular}

\subsection{Management of LDL-C}

Reductions in LDL-C level from baseline were found in both groups (Fig. 2a). Meanwhile, we found that LDL-C level of patients reported MACCEs was higher compared to patients without MACCEs or total 
patients (Fig. 2b). The proportions of patients achieved LDL-C goal were $50(11.6 \%)$ at baseline and 134 (31.0\%) at follow-up, respectively.

\section{Discussion}

In this present study, the main findings were as follows: (1) The patients achieved a LDL-C goal had a higher QFR and a lower DS\% or AS\% at one-year follow-up, indicating a better improvement in coronary physiology. (2) A positive consistent tendency was presented in coronary physiology assessment (higher QFR) and clinical outcome (lower incidence of MACCEs), which increases the support to LDL-C goal achievement recommendation from a perspective of multidisciplinary assessments.

In view of coronary physiology, we found that patients with lower level of LDL-C tend to have a higher QFR value at the time of follow-up. Yellow trial study has suggested that improvement in FFR is associated with lower level of LDL-C conducted by LLT [10]. The mechanism of FFR changes in patients treated with LLT is speculated upon plaque burden and endothelial function [15]. Ito T, et al. found that the plaque burden of a stented segment affects the FFR value rather than the luminal area after optimal drug-eluting stent implantation [16]. Another study by Kolozsvári $R$, et al. suggested that both luminal narrowing and plaque burden may affect the FFR derived from Computed Tomography (CT) scanning [17]. In addition, previous studies have shown that endothelial function may also affect the FFR value, albeit the mechanism is not completely understood $[18,19]$. QFR has a similar computational formula to FFR $[20,21]$. Thus, we hold the opinion that plaque burden and endothelial function are the main factors to influence QFR value in addition to narrowing lumen resulted from significant stenosis. Videlicet, a more satisfactory level of QFR value may reflect a better improvement in plaque burden or endothelial function in patients without significant stenosis.

Patients achieved LDL-C goal seemed to have a better result in coronary physiology assessment. Previous study concerning non-culprit plaque suggested that DS\% can increase by $2.2 \%$ even with routine LLT [22]. Our study showed a $0.6 \%$ increase in patients achieved a LDL-C goal, and a $3.3 \%$ increase in those not achieved goal, respectively. It seems that LDL-C goal achievement may alleviate the deterioration of non-culprit. In addition, LLL is an index to evaluate the absolute degree of restenosis and the status of the intimal hyperplasia in coronary artery [23]. No significant difference in LLL was found between two groups $(p=0.172)$, albeit the QFR value of patients achieved goal was higher $(p=0.005)$. Furthermore, lower incidence of physiological restenosis was recorded in goal-achievement group compared to non-achievement group. These QCA analysis results indicate that patients achieved a LDL-C goal may have a better improvement in coronary physiology. From the perspective of vascular physiology, the potential benefit of LDL-C goal achievement is verified.

The incidence of MACCEs was significantly lower in patients achieved a LDL-C goal. Previous studies have demonstrated clinical benefit from LLT, namely, the greater the absolute LDL-C reduction, the greater the cardiovascular risk reduction [24, 25]. Our study showed a consistent result concerning incidence of MACCE with previous researches. Nevertheless, no statistically significant differences were found in 
stroke, target or non-target vessel revascularization in our study. The small numbers of patients in these subgroups may account for this elusive statistical result. Although goal-achievement group not showed a statistical difference in revascularization, this group of patients was still reported with a lower incidence of revascularization in numerical result. Therefore, our finding suggests that LDL-C management is of significance in cardiovascular events prevention. In addition, a positive accordant tendency was presented in coronary physiology and clinical outcome, which provides new evidence to support the LDLC goal achievement recommendation.

For patients at very high cardiovascular risk, whether in secondary prevention or in primary prevention, a more aggressive LDL-C reduction goal are recommended according to The ESC/ EAS 2019 guidelines [3]. However, the proportion of patients achieved a LDL-C goal is still unsatisfied. In our study, only $31.0 \%$ of enrolled patients achieved a LDL-C goal even though the statin was prescribed to all participants. It may be due to the underdose of statin or insufficient concomitant use of other hypolipidemic drugs. Therefore, there is considerable potential to optimize lipid-lowering therapy further through statin intensification and appropriate use of novel LLT.

Our study still has some limitations. First, this is a observational study at a single center with a short time follow-up, the findings need to be verified by further prospective multi-center cohort studies. Second, some other treatment of risk factors may affect the incidence of MACCE, while not be discussed in our study. Third, not all images are suitable for QFR analysis, so it may affect the selection of some patients during QFR measurement.

\section{Conclusions}

Evaluated by QFR, patients who achieved the LDL-C goal seem to have a better coronary physiological benefit. Meanwhile, this group of patients is presented a better clinical outcome, which is in compliance with physiological assessment result. This study provides new evidence to support the LDL-C goal achievement recommendation from a perspective of multidisciplinary assessments.

\section{Declarations}

\section{Author contribution}

All authors designed the study. Long Chen, Jiaxin Zhong and Zhen Ye collected the data. Long Chen and Jiaxin Zhong did statistical analysis and wrote the article. Qin Chen, PhD and Yukun Luo, MD reviewed the article, Yukun Luo, MD is guarantor for this article. All authors gave final approval of the article.

\section{Conflicting interests}

The authors declared no potential conflicts of interest with respect to the research, authorship, and/or publication of this article 


\section{Funding}

This research did not receive any specific grant from funding agencies in the public, commercial, or notfor-profit sectors.

\section{References}

1. Anderson L, Thompson DR, Oldridge N, Zwisler AD, Rees K, Martin N, et al. Exercise-based cardiac rehabilitation for coronary heart disease. Cochrane Database Syst Rev. 2016;2016(1):Cd001800. doi:10.1002/14651858.CD001800.pub3.

2. Neumann FJ, Sousa-Uva M, Ahlsson A, Alfonso F, Banning AP, Benedetto U, et al. 2018 ESC/EACTS Guidelines on myocardial revascularization. Eur Heart J. 2019;40(2):87-165. doi:10.1093/eurheartj/ehy394.

3. 2019 ESC/EAS guidelines for the management of dyslipidaemias. Lipid modification to reduce cardiovascular risk (2019). Atherosclerosis, 290, 140-205, doi:10.1016/j.atherosclerosis.2019.08.014.

4. Baigent C, Blackwell L, Emberson J, Holland LE, Reith C, Bhala N, et al. Efficacy and safety of more intensive lowering of LDL cholesterol: a meta-analysis of data from 170,000 participants in 26 randomised trials. Lancet. 2010;376(9753):1670-81. doi:10.1016/s0140-6736(10)61350-5.

5. Boekholdt SM, Hovingh GK, Mora S, Arsenault BJ, Amarenco P, Pedersen TR, et al. Very low levels of atherogenic lipoproteins and the risk for cardiovascular events: a meta-analysis of statin trials. J Am Coll Cardiol. 2014;64(5):485-94. doi:10.1016/j.jacc.2014.02.615.

6. Catapano AL, Graham I, De Backer G, Wiklund O, Chapman MJ, Drexel H, et al. 2016 ESC/EAS Guidelines for the Management of Dyslipidaemias. Rev Esp Cardiol (Engl Ed). 2017;70(2):115. doi:10.1016/j.rec.2017.01.002.

7. Collaborative HProtectionS, G. Effects on 11-year mortality and morbidity of lowering LDL cholesterol with simvastatin for about 5 years in 20,536 high-risk individuals: a randomised controlled trial. Lancet. 2011;378(9808):2013-20. doi:10.1016/s0140-6736(11)61125-2.

8. Weintraub WS, Daniels SR, Burke LE, Franklin BA, Goff DC Jr, Hayman LL, et al. Value of primordial and primary prevention for cardiovascular disease: a policy statement from the American Heart Association. Circulation. 2011;124(8):967-90. doi:10.1161/CIR.0b013e3182285a81.

9. Schönbeck U, Libby P. (2004). Inflammation, immunity, and HMG-CoA reductase inhibitors: statins as antiinflammatory agents? Circulation, 109(21 Suppl 1), li18-26, doi:10.1161/01.Cir.0000129505.34151.23.

10. Kini AS, Baber U, Kovacic JC, Limaye A, Ali ZA, Sweeny J, et al. Changes in plaque lipid content after short-term intensive versus standard statin therapy: the YELLOW trial (reduction in yellow plaque by aggressive lipid-lowering therapy). J Am Coll Cardiol. 2013;62(1):21-9.

doi:10.1016/j.jacc.2013.03.058. 
11. Tu S, Westra J, Yang J, von Birgelen C, Ferrara A, Pellicano M, et al. Diagnostic Accuracy of Fast Computational Approaches to Derive Fractional Flow Reserve From Diagnostic Coronary Angiography: The International Multicenter FAVOR Pilot Study. JACC Cardiovasc Interv. 2016;9(19):2024-35. doi:10.1016/j.jcin.2016.07.013.

12. Song L, Tu S, Sun Z, Wang Y, Ding D, Guan C, et al. Quantitative flow ratio-guided strategy versus angiography-guided strategy for percutaneous coronary intervention: Rationale and design of the FAVOR III China trial. Am Heart J. 2020;223:72-80. doi:10.1016/j.ahj.2020.02.015.

13. Westra J, Andersen BK, Campo G, Matsuo H, Koltowski L, Eftekhari A, et al. (2018). Diagnostic Performance of In-Procedure Angiography-Derived Quantitative Flow Reserve Compared to PressureDerived Fractional Flow Reserve: The FAVOR II Europe-Japan Study. J Am Heart Assoc, 7(14), doi:10.1161/jaha.118.009603.

14. Tu S, Barbato E, Köszegi Z, Yang J, Sun Z, Holm NR, et al. Fractional flow reserve calculation from 3dimensional quantitative coronary angiography and TIMI frame count: a fast computer model to quantify the functional significance of moderately obstructed coronary arteries. JACC Cardiovasc Interv. 2014;7(7):768-77. doi:10.1016/j.jcin.2014.03.004.

15. Hashikata T, Tojo T, Muramatsu Y, Sato T, Kakizaki R, Nemoto T, et al. Lower Level of Low Density Lipoprotein Cholesterol is Associated with a Higher Increase in the Fractional Flow Reserve in Patients with Fixed-dose Rosuvastatin. J Atheroscler Thromb. 2018;25(3):233-43. doi:10.5551/jat.39560.

16. Ito $T$, Tani $T$, Fujita $H$, Ohte $N$. Relationship between fractional flow reserve and residual plaque volume and clinical outcomes after optimal drug-eluting stent implantation: insight from intravascular ultrasound volumetric analysis. Int J Cardiol. 2014;176(2):399-404. doi:10.1016/j.ijcard.2014.07.115.

17. Kolozsvári R, Tar B, Lugosi P, Sánta J, Béres Z, Ungvári T, et al. Plaque volume derived from threedimensional reconstruction of coronary angiography predicts the fractional flow reserve. Int $\mathrm{J}$ Cardiol. 2012;160(2):140-4. doi:10.1016/j.ijcard.2011.04.010.

18. Yoshino S, Cassar A, Matsuo Y, Herrmann J, Gulati R, Prasad A, et al. Fractional flow reserve with dobutamine challenge and coronary microvascular endothelial dysfunction in symptomatic myocardial bridging. Circ J. 2014;78(3):685-92. doi:10.1253/circj.cj-13-0846.

19. Takase S, Matoba T, Nakashiro S, Mukai Y, Inoue S, Oi K, et al. Ezetimibe in Combination With Statins Ameliorates Endothelial Dysfunction in Coronary Arteries After Stenting: The CuVIC Trial (Effect of Cholesterol Absorption Inhibitor Usage on Target Vessel Dysfunction After Coronary Stenting), a Multicenter Randomized Controlled Trial. Arterioscler Thromb Vasc Biol. 2017;37(2):350-8. doi:10.1161/atvbaha.116.308388.

20. Lansky AJ, Pietras C. Fractional flow reserve from 3-dimensional quantitative coronary angiography: fresh light through an old window. JACC Cardiovasc Interv. 2014;7(7):778-80. doi:10.1016/j.jcin.2014.05.002. 
21. Pijls NH, Fearon WF, Tonino PA, Siebert U, Ikeno F, Bornschein B, et al. Fractional flow reserve versus angiography for guiding percutaneous coronary intervention in patients with multivessel coronary artery disease: 2-year follow-up of the FAME (Fractional Flow Reserve Versus Angiography for Multivessel Evaluation) study. J Am Coll Cardiol. 2010;56(3):177-84.

doi:10.1016/j.jacc.2010.04.012.

22. Kang J, Park KW, Lee MS, Zheng C, Han JK, Yang HM, et al. The natural course of nonculprit coronary artery lesions; analysis by serial quantitative coronary angiography. BMC Cardiovasc Disord. 2018;18(1):130. doi:10.1186/s12872-018-0870-9.

23. Popma JJ, Leon MB, Moses JW, Holmes DR Jr, Cox N, Fitzpatrick M, et al. Quantitative assessment of angiographic restenosis after sirolimus-eluting stent implantation in native coronary arteries. Circulation. 2004;110(25):3773-80. doi:10.1161/01.Cir.0000150331.14687.4b.

24. Fulcher J, O'Connell R, Voysey M, Emberson J, Blackwell L, Mihaylova B, et al. Efficacy and safety of LDL-lowering therapy among men and women: meta-analysis of individual data from 174,000 participants in 27 randomised trials. Lancet. 2015;385(9976):1397-405. doi:10.1016/s01406736(14)61368-4.

25. Navarese EP, Robinson JG, Kowalewski M, Kolodziejczak M, Andreotti F, Bliden K, et al. Association Between Baseline LDL-C Level and Total and Cardiovascular Mortality After LDL-C Lowering: A Systematic Review and Meta-analysis. Jama. 2018;319(15):1566-79. doi:10.1001/jama.2018.2525.

\section{Figures}


All lesions underwent $\mathrm{PCl}$ and one year angiographic follow-up

(June 1,2015-December31,2016)

734 lesions (606 patients)

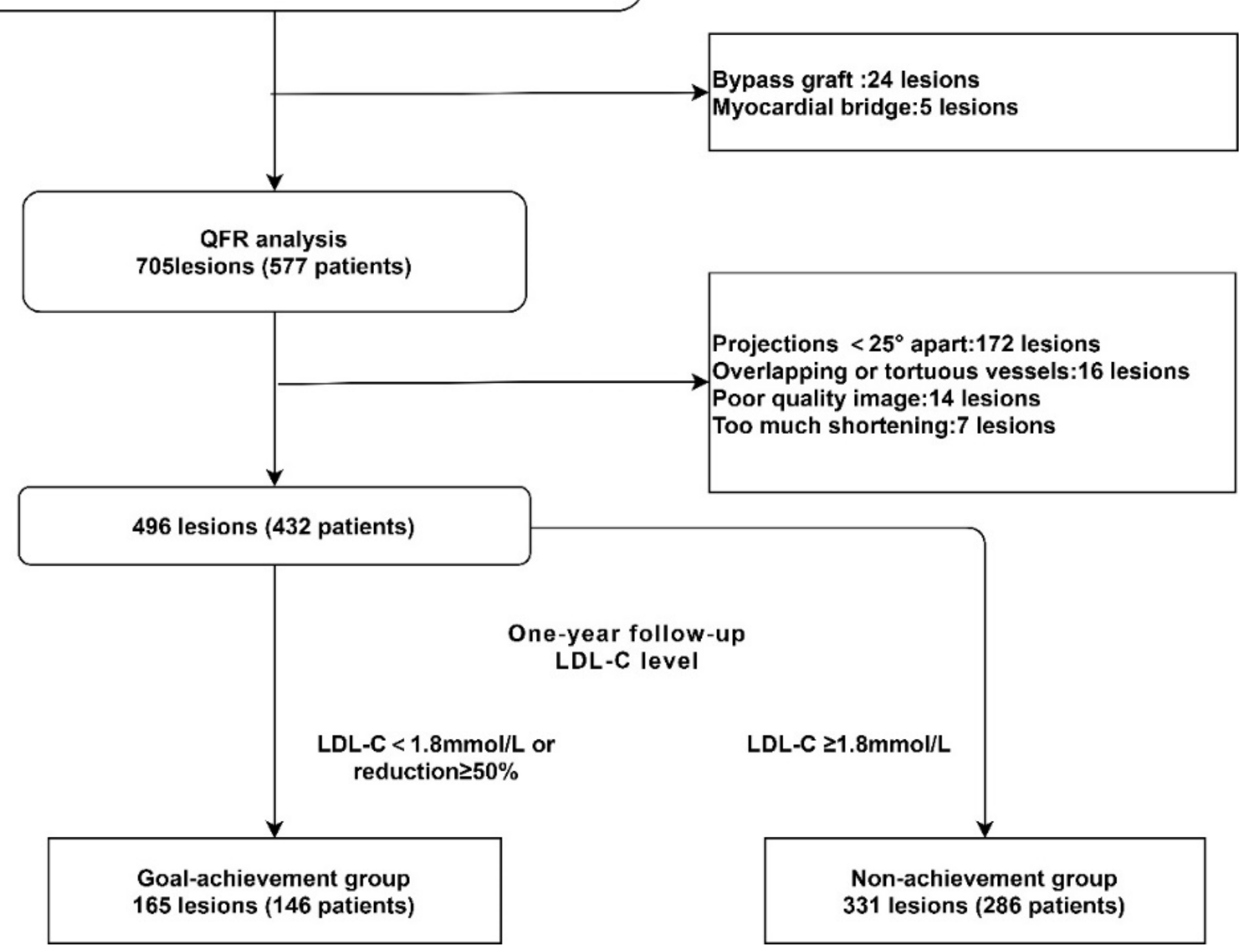

Figure 1

Study flowchart. Among 734 lesions in 606 patients underwent PCl, 705 lesions in 577 patients were analyzed by QFR. Of those, 172 lesions lack two optimal angiographic projections at least $25^{\circ}$ apart, 16 lesions were overlapping or tortuous, and 14 lesions in patients with poor quality image were excluded. Other 7 lesions were excluded due to excessive shortening lesions. Consequently, 496 lesions in 432 patients were analyzed in this study. According to the LDL-C level at the time of one-year follow-up, 165 lesions in 146 patients, and 331 lesions in 286 patients were assigned to goal-achievement and nonachievement group, respectively. QFR, quantitative flow rate; PCl, percutaneous coronary intervention; LDL-C, low-density lipoprotein cholesterol. 
$p=0.138$

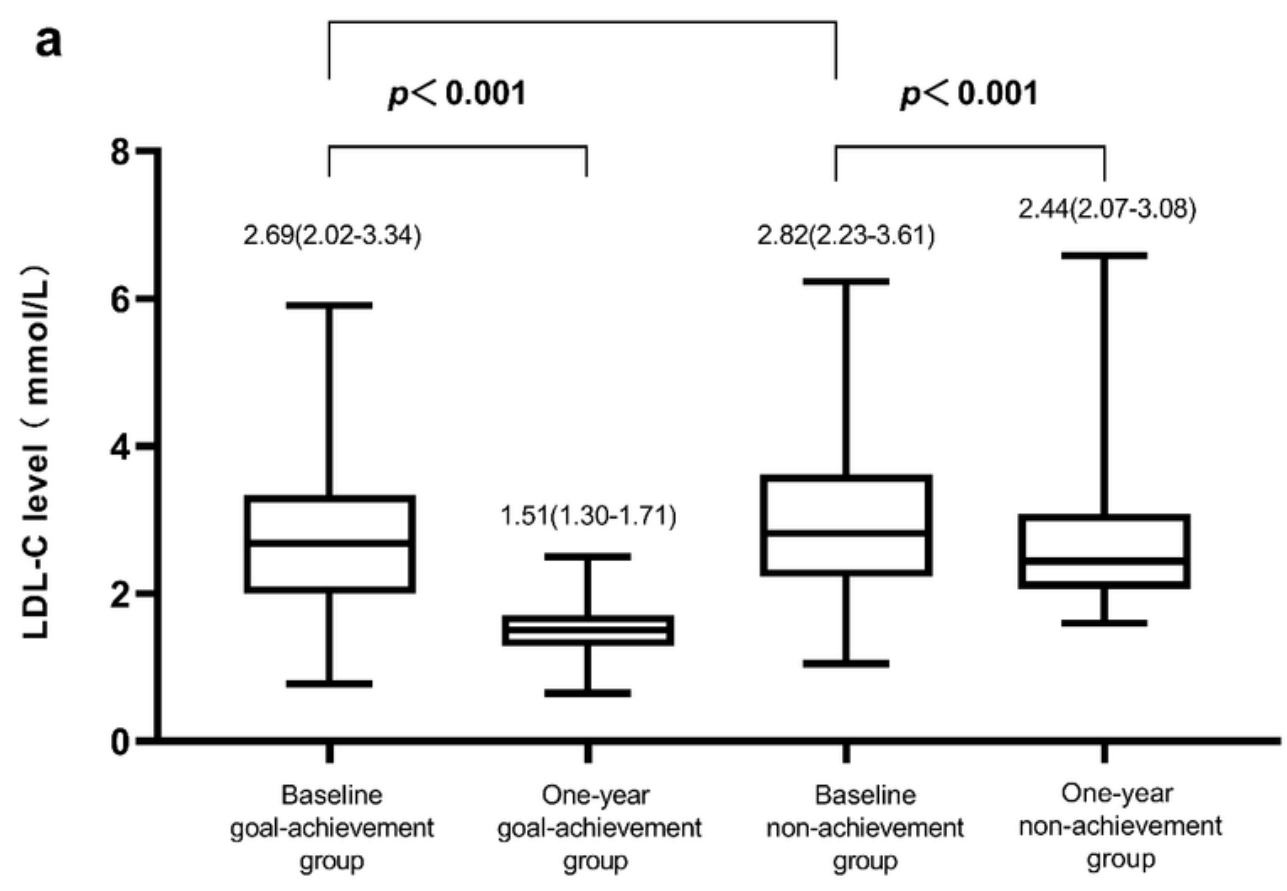

b

Figure 2

Variation of LDL-C level. 2a) Compared to baseline, LDL-C level were showed a reduction both in goalachievement and non-achievement group at the time of one-year follow-up. 2b) LDL-C level at the time of one-year follow-up in total patients, patients with MACCEs, and patients without MACCEs, respectively. 